In the Special Issue on Multicultural Social Justice Leadership Development Guest Editor: Carlos P. Zalaquett, University of South Florida

\title{
Implementing Multicultural-Social Justice Leadership Strategies When Advocating for the Rights of Lesbian, Gay, Bisexual, Transgender, Queer, and Questioning Persons
}

\author{
Michael D. Brubaker \\ University of Cincinnati
}

Amney Harper

University of Wisconsin Oshkosh

Anneliese A. Singh

The University of Georgia

\begin{abstract}
This article explores multicultural social justice leadership strategies in advocating with lesbian, gay, bisexual, transgender, queer, and questioning (LGBTQQ) individuals. In the current sociopolitical climate, there is a great need for counselors and counselor educators to become more involved in LGBTQQ advocacy. In response to this need, the authors developed a collaborative content session that was presented at the Multicultural Social Justice Leadership Development Academy at the 2010 American Counseling Association Conference. The session was geared towards increasing the knowledge, awareness, and skills of multicultural social justice leaders who are advocating with $L G B T Q Q$ individuals and communities. In this article, the content of the session and the personal narratives of the presenters are reviewed, along with the recommendations and considerations that were discussed. Additionally, audience participation in the session is discussed along with the action strategies that were collaboratively developed as a part of the session.
\end{abstract}

Keywords: gay, lesbian, queer, transgender, advocacy, social justice 
There has never been a greater need for multicultural-social justice leadership training among counselors than at the present time. Ironically, the need is great despite the current advances in the social-political climate which might cause counselors to view this era as a time when those who identify as lesbian, gay, bisexual, transgender, queer, and questioning (LGBTQQ) have achieved greater acceptance than ever before. Following the call of the Association for Lesbian, Gay, Bisexual, and Transgender Issues in Counseling (ALGBTIC), the American Counseling Association (ACA) endorsed Competencies for counseling LGBT individuals (Frank \& Cannon, 2010). These competencies are currently being revised and expanded. Furthermore, competencies specifically for counseling individuals who identify as transgender (ACA, 2009) have been approved. The ACA Code of Ethics (2005) uses clear language to condemn discrimination against clients on the basis of sexual orientation or gender identity. By these institutional developments alone, there appears to be significant progress in advocating for the rights of the LGBTQQ community.

Unfortunately, these reforms are not always respected within the counseling profession and oppression continues in society at large. Even though the ACA Ethics Committee has formally indicated that counselors practicing conversion therapy fail to abide by the Code of Ethics (Whitman, Glosoff, Kocet, \&Tarvydas, 2006), there remain a vocal number of practicing counselors who insist that such practices have merit and should remain viable alternatives for clients seeking to change their sexual orientation or gender identity and expression(Hamilton \& Henry, 2009). Furthermore, those in same-sex relationships continue to face discrimination through laws and policies that ban marriage, visitation rights for children of same-sex couples, and partner benefits (Singh, 2010).

Despite the many years of political wrangling, federal protections against discrimination of LGBTQQ in the workplace are very limited and there is yet to be acceptance for military personnel who are "out" while serving their country (Human Rights Campaign, 2010). Even the academic community has become affected by a conservative swing in attitudes as universities have removed anti-discrimination policies that previously protected all sexual orientations from discrimination and harassment on specific college campuses (Helderman, 2010). Most universities do not even have such policies in place, especially protections for all gender identities and expressions (Baez, 2007). Therefore, it is expected that even counselor education programs have been found lacking in their ability to effectively train counselors-in-training to serve LGBTQQ persons (Frank \& Cannon, 2010).

When considering current events, a reality that often gets further obscured is the multiple identities and oppressions that members of the LGBTQQ communities face. For example, as same sex marriage rights or employment non-discrimination is discussed, it is often forgotten that other identities (e.g., ethnicity, gender, socio-economic status) can further impact individuals' experiences with oppression (Wynn \& West-Olatunji, 2008). Understanding the complex nature of oppression is a must for counselors, counselors-in-training, counselor educators, and related professionals, and activism that promotes social justice for all members of the LGBTQQ communities is especially necessary in today's social, political, and economic climate. 
Multicultural-social justice leadership training with regard to LGBTQQ issues in counseling is necessary to facilitate positive social change in both the counseling profession and within society as a whole. Social justice leadership occurs when people "make issues of race, class, gender, disability, sexual orientation, and other historically and currently marginalizing conditions in the United States central to their advocacy, leadership practice, and vision" (Theoharts, 2007, p. 223). Understanding the interconnectivity between the social justice and multicultural movements, D'Andrea and Heckman (2008) suggested that both be recognized concurrently as multicultural social justice (MSJ) work. In the following sections, the authors describe the content of an MSJ leadership training session for counselors and other professionals who advocate for LGBTQQ persons. Through audience comments and presenter responses, the session's community of leaders co-created a set of future action strategies that would be implemented over the following year prior to the ACA Conference in New Orleans.

\section{MSJ Session Content Overview}

This 90-minute session was divided into three phases, including the foundational knowledge of LGBTQQ issues in counseling, specific leadership strategies when advocating with LGBTQQ persons and communities, and a series of narratives by the three presenters sharing their personal MSJ leadership experiences. By establishing a baseline of shared knowledge and offering these experiences, participants were encouraged to reflect on their own experiences so that together, all may collaborate on strategies that may be implemented after the close of the session.

\section{Building a Foundation of LGBTQQ Knowledge}

To begin the session, the presenters offered a brief Queer and Transgender 101, giving voice to the language of those who identify as lesbian, gay, bisexual, transgender, queer, and questioning. The presenters energized the room with a call and response format of a series of queer-based words to encourage a playfulness that could remove the shame often imposed by social stigma. The concept of microaggressions was defined as "brief and commonplace daily verbal, behavioral, or environmental indignities, whether intentional or unintentional, that communicate hostile, derogatory, or negative racial slights and insults toward people of color." (Sue, Bucceri, Lin, Nadal, \& Torino, 2007, p. 273) to help explain the subtle ways oppression is perpetuated in common interactions. Additionally, the presenters set a backdrop through giving a brief overview of current events both within the counseling profession and also within a national context for LGBTQQ individuals and communities.

The session continued with a call to increase awareness by committing to becoming more educated on issues related to sexual orientation and gender identity/expression. It was noted that this occurs through the study of formal literature and through informal interactions where understanding is gained by sharing personal stories with one another. Such exchanges provided echoes of the mantra "Silence = Death," so commonly declared by AIDS activists in the late 1980s (Smith, 1998/2001). Presenters also highlighted the importance of counselors connecting to LGBTQQ communities in their localities as a way to understand and also have their "finger on the pulse" of how they can best serve and advocate with LGBTQQ individuals. 
In addition, the ecological concepts of the micro-, meso-, and macro-systems (Bronfenbrenner, 1977) were introduced as a means of analyzing the source of oppression and levels of interventions that would be necessary. Although advocacy is needed at all levels, there are strategies that target particular levels, which may be more effective given the context in which oppression occurs. Once connected to LGBTQQ communities, counselors can more adequately assess needs and plan interventions at the appropriate level. As each system affects the others, any intervention can have an impact that reaches beyond individual action. Counselors also may have differing levels of expertise, access, or comfort in advocacy at each level, each of which needs to be considered when intervening. All of these factors must be considered with working together in community to advocate for change.

\section{Developing Leadership Strategies when Advocating with LGBTQQ Persons}

Advocating for LGBTQQ persons can be a disempowering act. Through the years, there have been multiple pressures for queer individuals to be silent and disempowered from the Nazi Holocaust camps through the current military "Don't Ask Don't Tell" policy. The ACA Advocacy Competencies (Lewis, Arnold, House, \& Toporek, 2003) are helpful in this regard as they describe times when it is most appropriate to "act with" or "act on behalf" of people experiencing oppression like the LGBTQQ community. There may be times when it is appropriate to act on behalf of LGBTQQ individualsand in these cases it is important to ensure that the individuals and communities are being represented as they would choose.

For example, there are times when an LGBTQ individual is not heard because of perceptions about them related to their identity or when the cost is too high for LGBTQ individuals to speak out, and they would prefer to have someone else to speak out on their behalf. While the ideal situation is always to act with, there are circumstances where acting on behalf can be important too, especially when the weight of oppressive institutions threatens the safety and well-being of those who would otherwise advocate for themselves.

MSJ leadership requires being willing to take risks by "rolling up the sleeves" and actively engaging other community leaders as well as opposing forces. By listening to and acting with the community, leaders will have a better understanding of others in that community, understanding the complexity that defies common stereotypes.

Leaders need to be multiculturally competent, recognizing the intersectionality of many identities (Wynn \& West-Olatunji, 2008). It is tempting to oversimplify sexual orientation and gender identity, failing to see how race, ethnicity, age, ability, geography, social class, and other dimensions of identities influence one another. Just as individuals are complex, so are communities. Some have greater consciousness than others about the ways that society has imparted negative values that get used to disempower others. Alternatively, there are great strengths that are often overlooked when such complexity is ignored.

During the session, the presenters offered that oversimplification is exemplified in the false dichotomy between religion and queer identities. The acts of a few within the conservative religious community often overshadow the fact that many LGBTQQ individuals engage in spiritual and religious practices (Rostosky, Riggle, Brodnicki, \& Olson, 2008). Historically, many religions in pre-colonial times were affirming of same-sex practices and intersex gender identity, realizing the sacred nature of such persons (Garrett \&Barret, 2003; Feinberg, 1997; Singh, 
Whitman, \& Boyd, 2010). Even today, there are many religious communities that are LGBTQQ affirming.

A key leadership strategy the presenters identified was effective messaging. When advocating with LGBTQQ persons, being effective means being affective. The Georgia Safe Schools Coalition (GSSC, 2009) outlines nine strategies for effective messaging. The first is to know your audience when engaging in advocacy, as one's message will shift according to who is in the audience. Second, being respectful is a critical aspect of delivering a message people can hear. Third, finding common ground is a salient goal especially on LGBTQQ advocacy. For instance, exploring a goal of "keeping all youth safe" might be an effective common ground between people with disparate views on LGBTQQ issues. Fourth, being mindful of language is key to ensuring a message builds common ground or furthers a divide on LGBTQQ issues. Fifth, developing a primary message and supporting messages is important. Sixth, reframing the conversation is a primary skill to ensure advocacy on LGBTQQ issues addresses myths and stereotypes. Seventh, counselors should consider opposition framing so they are prepared to address misinformation and misunderstanding. Eighth, because LGBTQQ issues can bring up strong emotions, it is important to consider sharing a personal message when applicable about counselor experience with LGBTQQ issues, individuals, and communities. Substantial change often occurs when hearts and minds are touched and the message becomes personal. Finally, practice and preparation is a large component of being able to anticipate areas of difference and delivering a cohesive message on LGBTQQ advocacy.

\section{Sharing Three Narrative Examples of MSJ Leadership}

In order to demonstrate the application of these leadership advocacy strategies, the presenters shared their experiences in the $\mathrm{K}-12$ school system, on university campuses, and in an urban community setting. Each is shared below:

A story of multi-level advocacy and "acti-vision." The Georgia Safe Schools Coalition (GSSC) was a collaborative project that I (Anneliese) initiated with the purpose of recruiting effective LGBTQQ youth advocates, safe schools activists, and other individual and community organizations working on safer school issues for LGBTQQ youth. Within a year's time, the coalition had become an important force in advocacy and activism as it was able to lobby, write press releases on LGBTQQ issues during various crises, and take risks that other government and nonprofit organizations might not have been able to undertake due to the boundaries of their organizational advocacy.

There are seven GSSC activities that may prove helpful to other counselors looking to engage in LGBTQQ advocacy for students. First, the coalition members designed a Comprehensive Manual for School Counselors working with LGBTQQ youth (see www.GeorgiaSafeSchoolsCoalition.org to download manual components) and distributed this in paper and online formats. Second, we designed a GSSC Safe Zone Sticker with the logo as the state of Georgia with a rainbow background to indicate support of LGBTQQ youth. The coalition set an ambitious and important goal of having GSSC Safe Zone stickers in each school in Georgia, so there is an ongoing mission and accountability mechanism for the coalition members. GSSC has provided trainings for those school counselors and educators who display a GSSC Safe Zone sticker in their classroom. Third, the coalition has used technology for organizing (e.g., Facebook, Twitter, texting, email). GSSC has also worked with local university interns in technology to develop a 
website (www.GeorgiaSafeSchoolsCoalition.org) that outlines the coalition's activities, ways to partner with the coalition, stories of LGBTQQ advocacy in schools, and resources specific to Georgia so that counselors in rural and/or other isolated areas may be connected to GSSC. Fourth, we have prioritized activism and lobbying, such as attending school board meetings to advocate for specific categories of sexual orientation and gender identity and expression to be included in school bullying policies. Fifth, GSSC members do not rest on their current knowledge on LGBTQQ issues and seek to further their learning of the intersections of heterosexism and transprejudice with other oppressions such as racism, classism, and ableism. Therefore, community collaborations have been important places where coalition members have furthered their learning through volunteer work and participation (i.e., community collaborations such as the Transgender Day of Remembrance supporting transgender people and the Bayard RustinAudre Lorde brunch supporting queer and transgender people of color). Sixth, because a common response from school personnel on LGBTQQ youth issues was that "we don't have those types of kids here," the coalition worked with local filmmakers to develop documentary films on Georgia LGBTQQ youth stories (Singh \& Johnson, 2009; Singh \& Johnson, 2010). Finally, we have sought to be strategic in "mapping the state" for a "Train-the-Trainers" session on LGBTQQ youth to ensure there is a GSSC-trained educator in each county who can be a local resource to a county school.

A story of personal/professional and regional considerations.I (Amney) began my LGBTQQ activism in the South during my graduate training, and have continued in the Midwest where I work now. During my graduate training at Auburn University in Alabama, several graduate students and I conducted an informal research project polling over 100 universities about their services and protections for LGBTQQ students. From this research, a model was created that outlined optimal services on college campuses for LGBTQQ students. These findings were presented at the Georgia ALGBTIC Annual Day of Learning Conference in 2006 (Owens, Doolin, Downes, Graham, Harper, \& Hatchman, 2006). After the presentation, two of the presenters and I decided to begin advocating on our own campus in order to improve the services currently available. From these various acts of advocacy, some considerations where shared with audience members to use in their own work.

The first of these considerations is to know the needs of your region and/or community. Each region or community has its own way of communicating its identities, needs, and struggles. Additionally, different regions also vary in the ways that homophobia, transphobia, biphobia, racism, sexism, etc. manifest themselves. Each LGBTQQ community is also situated within the broader community, which varies in many ways, such as its political climate. In Alabama, for example, it is very politically conservative. Due to the unique culture and climate, our first acts of advocacy were targeted at promoting education on LGBTQQ individuals and issues. Additionally, in order to utilize the language of the Auburn community in our advocacy work, we framed our request to have sexual orientation, gender identity, and gender expression included in the campus anti-discrimination policy through talking about "keeping every member of the Auburn family safe." The Auburn family is a concept that is rooted deep in the hearts of most Auburn students, faculty, staff, alumni, and administrators as it represents pride for the university and a traditional value of family. We were successful in getting sexual orientation added to the policy, however, gender identity and gender expression remain unprotected categories in the university policy. There are many members of the Auburn family who continue to advocate for the full protections of gender identity and gender expression. 
The second consideration is to create a platform from which to build your advocacy work. In Alabama, we founded Spectrum Alliance, a graduate, non-traditional, and professional student support group. Using this group as a platform allowed us access to resources (such as meeting spaces, the ability to set up tabling on the concourse, access to faculty mentors, etc.).

Additionally, through creating a group we developed a presence on campus to live beyond any particular student leaders and members, who eventually graduate or leave the university. The group also was able to utilize its position on campus to mentor undergraduate leaders and collaborate with the undergraduate LGBTQQ group for events and activities. We utilized the model we had created to target those areas most needed (e.g., to establish a Safe Zone training program, to get basic protections for LGBTQQ students, and to promote an inclusive and welcoming climate for LGBTQQ students) on our campus to further our mission and goals for the group's role on campus.

Similarly, when I came to the University of Wisconsin Oshkosh, I immediately sought out a way to get connected to the LGBTQQ advocacy on campus. Much of the work of faculty and staff is done through the LGBTQ Council, the official university LGBTQQ committee, including coordinating all SAFE Trainings, campus education, and advocacy efforts. However, university committees have limitations because they have formal structures and roles and operate at the behest of the university. In order to fill in the gaps, we founded EQuAL (Employee Queer and Ally League), a faculty, staff, graduate/non-traditional student support and advocacy group. Since EQuAL has no official charge from the university, it can create its own roles and tasks according to the needs and desires of its members. Its structure also accommodates unlimited membership, making it a good platform to build a strong LGBTQQ community. Though EQuAL is still fairly new to the campus, it has taken an active role in connecting to undergraduate students (providing mentorship and support) as well as leading and co-sponsoring a week of transgender education and advocacy to support the move to promote gender neutral bathrooms on campus.

The final consideration discussed was the personal impact of coming out and advocating. Something that is rarely discussed is the difficulty of being an out LGBTQQ leader. As a faculty member, I have found there are many benefits of being out, such as providing LGBTQQ students who may not be out with a positive role model and a safe person with whom to discuss the implications of being an LGBTQQ counselor. Although it may become routine to come out in public spaces, it can still be stressful for both LGBTQQ individuals or heterosexual, cisgender allies (cisgender is defined as those individuals whose gender identity matches the "expected" gender identity of their sex assigned at birth) (D'Augelli, 2002; Floyd \& Stein, 2002; Iwasaki \& Ristock, 2007). As advocates, we are particularly aware of the various oppressions that impact our communities. These issues, especially when paired with personal experiences of oppression, can create large personal stress. As counselors and counselor educators, we understand the importance of self-care (McMahan, Singh, Urbano, \& Haston, 2010), as demonstrated by its inclusion in the CACREP Standards (2009). However, the role of advocate for counselors and counselor educators provides an additional layer to the day-to-day stresses of our work (Holeman, 2005; Singh, Urbano, McMahan, \& Haston, 2009). For me, connecting to colleagues doing similar work and connecting to the LGBTQQ community are integral ways of regenerating from the various stresses of advocacy. I also find there are times when I am more prepared to speak out than others. It is important for me when I am feeling particularly vulnerable in the role of advocate to acknowledge my feelings and have someone to talk with 
about them (Holeman, 2005; Singh et al., 2009). Also, I have to allow myself to step back when I need to, and jump back in when I am ready.

A story of research and social marketing. As a graduate student, I (Michael) joined a research team led by Dr. Brian Dew, Associate Professor and Counselor Educator at Georgia State University. At the time, methamphetamine use was rampant among gay men, many of whom were HIV positive and were less likely to use condoms or other safe-sex practices while intoxicated (Dew, Sterk, Elifson, \& Brubaker, 2006; Kurtz, 2005). Using the principles of MSJ leadership, the team built a sustained relationship with the Atlanta Methamphetamine Task Force, the leading advocacy group in Atlanta for those recovering from methamphetamine addiction. In the spirit of the community as client model (West-Olatunji \& Watson, 1999), the research team sought to build a collaborative atmosphere, designing surveys and collecting data together to meet the purposes of reducing methamphetamine use in the gay male community. Trust and credibility were essential, both of which were developed over time largely by Dr. Dewbut reaffirmed by the team's willingness to participate in many advocacy projects in town. Students, faculty, and community members quickly bonded as all worked to secure financial and volunteer resources to research the attitudes of the community and develop an effective social marketing campaign.

As the research team was comprised of gay, lesbian, bisexual, and straight allies, many team members ventured into settings to collect data that they would not have done otherwise. Research members attended the opening day of Brokeback Mountain movie, gay fitness centers, leather bars, dance clubs, and retail stores frequented by the LGBTQQ community. This afforded members the opportunity to learn and grow from one another through these shared experiences, reaffirming the credibility of the team with the community.

From this collaborative partnership with the community, two primary messages were brought back to the community. The first built upon the "Silence=Death" message heard first during AIDS crisis of the 1980s, now translated to "Meth=Death." By giving voice through the survey process, it was clear that the LGBTQQ community did not think favorably of the impact of this drug on its members. This message presented the sentiments of survey participants.

The second message built upon the Gay, Lesbian, and Straight Education Network (GLSEN) principle of knowing your audience was the recognition that sexual orientation and southern religious culture are frequently intertwined. This message was "God will not send you to hell, but Tina will." Tina is the common street term for methamphetamine. The often internalized message that being gay is sinful was challenged, while the hellish realities of methamphetamine use were reaffirmed. These messages were presented in the local LGBTQQ magazine, on a popular billboard, on t-shirts worn at the Pride festival, and through a dramatic coffin-carrying act at the Pride parade. Through effective MSJ advocacy, the community was empowered to give voice to the atrocities of this epidemic, while providing opportunities for research members and community activists to grow together.

\section{MSJ Participant Comments and Presenter Responses}

There was a rich, mutual discussion during the presentation between the presenters and participants, with regular pauses for translating discussed strategies to real-life situations participants described facing in their counseling settings. One counselor educator was 
interested in learning more about the American Counseling Association Competencies for Counseling Transgender Clients (2009) in order to support an incoming student in her program. The presenters emphasized the feminist, social justice, multicultural, and strength-based frameworks upon which the competencies were grounded and directed her to the ALGBTIC website to download the competencies document. Other participants who worked in schools resonated with the needs of LGBTQQ youth and shared difficulty they faced in advocating for these youth in school settings.

A major theme that emerged from this discussion was the intersection of religious beliefs and advocacy needs of LGBTQQ youth and adults. The presenters had challenged the false dichotomy of religion and LGBTQQ issues, and the participants responded with stories of how their religion and spiritual beliefs guided them to make more of a commitment to advocacy on behalf of LGBTQQ issues. For instance, one participant discussed her religious beliefs as a Christian and how the commandments of love, compassion, and service to her community helped her manage difficult conversations about LGBTQQ issues and religion. Similarly, another participant discussed how his Buddhist beliefs allowed him to explore LGBTQQ clients' religious and spiritual beliefs as a source of coping. The presenters engaged in this discussion and commented that advocacy on LGBTQQ issues also includes helping other counselors in our settings develop the awareness, knowledge, and skills to support discussions on religion and LGBTQQ issues that are not divisive, but rather focus on a common goal of supporting the wellbeing of LGBTQQ persons. These personal stories provided the impetus to establish a number of activities that participants and presenters alike could implement over the coming year.

\section{Future Action Strategies for MSJ Leadership on LGBTQQ Issues}

Emphasizing the practical and action-oriented nature of multicultural-social justice counseling, the presenters invited participants to strategize about future action strategies in their respective settings. The audience agreed to collaborate in this dialogue, with individual members making personal and informal commitments to take action within the next year. Ideally, these commitments would have been made into a formal action plan for the group, a suggested improvement for future session of this type. Each of the strategies discussed at this culminating stage was recorded by the session facilitator and expounded upon below.

\section{Become More Active in Community/LGBTQQ Activities}

The theme of collaboration was embraced as the group agreed to become more involved with LGBTQQ communities. By participating in local activities, meeting with leaders, and working together with those striving for justice, all may join forces instead trying to advocate from isolated bases of support. Collaborative efforts between ACA divisions and regions on LGBTQQ issues are an example of how this vision can be realized. ACA has had a strong track record of supporting and advocating for LGBTQQ issues in counseling. Building on ACA's strengths in this regard, Governing Council and the Council of Presidents and President-Elects could collaborate across divisions and regions to implement the competencies with transgender clients (ACA, 2009) and other best practices for working with LGBTQQ clients. Other activities involving collaborations might include helping start a support group in a counselor's local setting for LGBTQQ youth or planning and participating in a Transgender Day of Remembrance (see www.tdor.org for planning resources). 


\section{Engaging in Activism}

Action oriented steps must be undertaken to realize concrete changes in our society. Although there are many opportunities to act globally and nationally, it is also important to think locally within our own communities. MSJ leaders are therefore called to create justice by challenging oppression in the many forms that it occurs for LGBTQQ people. Activism may seem overwhelming to consider for many counselors whose time is limited or whose setting is underresourced (Singh, 2010). However, there are many simple strategies that may be conducted in collaborative ways - such as writing a brief editorial in the local newspaper on addressing LGBTQQ-bullying in schools in collaboration with a local LGBTQQ activist or supporting LGBTQQ people in conducting a local action in their schools or community settings.

\section{Modeling and Normalizing the Conversation on LGBTQQ Issues}

As part of this local activism, open conversations about LGBTQQ issues can help to normalize the conversation and provide examples for others to do the same. Just as the session began with the presenters demystifying LGBTQQ language, there is no need to carry shame or whisper the words queer, lesbian, gay, or the like. The vision is for safe spaces to expand across our society and that hate and shaming behaviors will no longer have such power.

\section{Identifying Ways to Improve Schools' Openness to LGBTQQ Issues}

There is no greater place where modeling and normalizing can occur than in the schools. As the Georgia Safe Schools Coalition's work has demonstrated, collaborative advocacy strategies can be an effective approach to building networks of change agents willing to learn and grow together while creating safe spaces for youth in schools. It is expected that these strategies may be adapted and built upon in other school systems.

\section{Working to Pass LGBTQQ-Affirmative Policies and Laws}

There continues to be great need in traditional political advocacy work, lobbying legislators to create and support laws that protect the rights of LGBTQQ individuals. The National Gay and Lesbian Task Force (the taskforce.org), The National Center on Transgender Equality (www.ncte.org), and the Human Rights Campaign (www.hrc.org) list helpful resources on their websites to identify current legislative activity concerning LGBTQQ issues, in addition to direct ways to engage in legislative advocacy. As individuals and organizations collaborate together further, power can be amassed to elect new legislators and persuade current ones to be make positive social change on LGBTQQ issues.

\section{Continue Learning about Ever-Evolving Gender/Sexuality Issues}

As proposed in the session, it was agreed that all must continue to grow in experiences and knowledge about gender and sexuality issues. There is an ever-evolving base of research that is being published, documenting the experiences of LGBTQQ individuals and ways to promote greater wellness. Practitioners who are newer to LGBTQQ advocacy efforts can begin with this step, learning more about the lives of the queer and transgender community and attending social and political events that are important to LGBTQQ individuals. This, in addition to the 
many daily experiences with people of diverse sexual identities and gender expressions, may provide rich opportunities to learn from one another.

\section{Advocate Globally for LGBTQQ Individuals and Communities}

Discrimination against those who differ from the cisgender, hetero-normative identity occurs across the globe, not just in the United States (Singh, 2010). One recent example is the proposed Ugandan legislation that would impose criminal penalties, including death, for engaging in "homosexual acts." Same-sex marriage could result in life imprisonment, and not reporting such activity to the authorities can result in criminal charges (Anti-Homosexuality Bill, 2009). LGBTQQ communities exist worldwide and need MSJ advocacy and support. Advocacy efforts in this case may be conducted through lobbying United States congressional representatives and the State Department for their support, as well as by offering education to non-profit aid organizations that serve areas that are hostile to LGBTQQ individuals.

Having heard the comments of the audience members in this collaborative process, the presenters were challenged to consider how they could expand their MSJ efforts in future projects. Finding ways to impact the larger community was one significant challenge. Each of the projects shared could be expanded to impact the national and international communities through legislative lobbying, publications, and global advocacy. The writing of this article was, in part, a response to this need to share these activities with a larger audience.

\section{Conclusion}

Although there are many facts and news stories that document the atrocities of oppression experienced by the LGBTQQ community, injustices often remain unnoticed until there is a personal connection to these events. The need to listen to and share with one another in the community may be one of the most important lessons of this session. Not only was this truth emphasized among the strategies mentioned, it was practiced in the dialogue between participants and presenters, which evolved into general strategies that individuals chose to embrace over the coming year. These personal connections within community are foundational when building bases of support, increasing self-awareness, and learning more deeply about the individual struggles and strengths among each other.

This session provided a number of strategies that can be used by leaders to advocate for the rights of lesbian, gay, bisexual, transgender, queer, and questioning persons. Building on a foundational understanding of the LGBTQQ community and basic advocacy strategies, the presenters and participants offered examples of MSJ leadership strategies that they have used. These personal connections became the base for a discussion about particular action strategies that could be implemented over the course of the coming year. This article not only documents this session, but it serves as a challenge to all readers to implementing these strategies within their own settings and abroad. As this group reconvenes in New Orleans in 2011, all are invited to join together to share how these activities have been implemented over the past year, offering the lessons of their accomplishments and shortfalls, and describing how personal lives have been changed. 
Contact information/Correspondence:

Michael D. Brubaker, Ph.D.

School of Human Services

University of Cincinnati

502 Dyer Hall, PO Box 210068

Cincinnati, $\mathrm{OH}, 45221-0068$.

Email: michael.brubaker@uc.edu

Michael D. Brubaker, Ph.D, Assistant Professor in the School of Human Services at the University of Cincinnati; Amney Harper, Ph.D, Assistant Professor in the Department of Professional Counseling at the University of Wisconsin Oshkosh. Anneliese A. Singh, Ph.D, Assistant Professor in the Department of Counseling and Human Development Services at The University of Georgia. The authors would like to thank the session participants for their contributions and dedication to collaboratively developing the advocacy strategies discussed in this manuscript.

\section{References}

American Counseling Association (2005). ACA code of ethics. Alexandria, VA: Author.

American Counseling Association. (2009). Competencies for counseling gay, lesbian, bisexual and transgender clients. Retrieved from http://www.algbtic.org/competencies.html

Anti Homosexuality Bill, Uganda Parliament 18, (2009, September 25). Uganda Gazette. Retrieved from http://www.boxturtlebulletin.com/btb/wp-content/uploads/2009/10/BillNo-18-Anti-Homosexuality-Bill-2009.pdf

Baez, J. (2007). The gay and lesbian guide to college life: A comprehensive resource for lesbian, gay, bisexual, and transgender students and their allies. New York: Random House.

Bronfenbrenner, U. (1977). Toward an experimental ecology of human development. American Psychologist, 32(7), 513-531. doi:10.1037/0003-066X.32.7.513

D'Andrea, M., \& Heckman, E. F. (2008). Contributing to the ongoing evolution of the multicultural counseling movement: An introduction to the special issue. Journal of Counseling \& Development, 86, 259-260.

D'Augelli, A. R. (2002). Mental health problems among lesbian, gay, and bisexual youths ages 14 to 21. Clinical Child Psychology and Psychiatry, 7(3), 433-456. doi:10.1177/1359104502007003039

Dew, B. J., Sterk, C., Elifson, K., \& Brubaker, M. (2006). Drug trends in metropolitan Atlanta. In National Institute of Drug Abuse. Epidemiologic trends in drug abuse, Vol. 2, 
Proceedings of the Community Epidemiology Working Group. U.S. Department of Health and Human Services: National Institutes of Health, 5-16.

Feinberg, L. (1997). Transgender warriors: Making history from Joan of Arc to Dennis Rodman. Boston, MA: Beacon Press.

Floyd, F. J., \& Stein, T. S. (2002). Sexual orientation identity formation among gay, lesbian and bisexual youths: Multiple patterns of milestone. Journal of Research on Adolescence, 12(2), 167-191. doi:10.1111/1532-7795.00030

Frank, D., \& Cannon, E. P. (2010). Queer theory as pedagogy in counselor education: A framework for diversity training. Journal of LGBT Issues in Counseling, 4(1), 18-31. doi:10.1080/15538600903552731

Garrett, M. T., \& Barrett, B. (2003). Two Spirit: Counseling Native American gay, lesbian, and bisexual people. Journal of Multicultural Counseling and Development, 31, 131-142.

Georgia Safe Schools Coalition (2009). Effective messaging: communicating with parents and school personnel. Georgia: Author. Retrieved from georgiasafeschoolscoalition.org

Hamilton, J. H., \& Henry, P. J. (Eds.). (2009). Handbook of therapy for unwanted homosexual attractions: $A$ guide to treatment. Longwood, FL: Xulon Press.

Helderman, R. S. (2010, March 6). Attorney general asks colleges to end policies that shield gays. The Washington Post, p. A1.

Holeman, H. (August, 2005). The emotional costs of activism: Visiting the front lines. $A$ qualitative inquiry. Washington, D.C. American Psychological Association Division 17 Student Poster Session.

Human Rights Campaign (2010). Federal legislation. Retrieved from http://www.hrc.org

Iwasaki, Y., \& Ristock, J. L. (2007). The nature of stress experienced by lesbians and gay men. Anxiety, Stress \& Coping: An International Journal, 20(3), 299-319. doi:10.1080/10615800701303264

Kurtz, S. P. (2005). Post-circuit blues: Motivations and consequences of crystal meth use among gay men in Miami. AIDS and Behavior, 9, 63-72. doi: 10.1007/s10461-005-1682-3

Lewis, J. A., Arnold, M. S., House, R., \& Toporek, R. L. (2003). ACA Advocacy Competencies. Retrieved from http://www.counseling.org/Publications.

McMahan, E. H., Singh, A. A., Urbano, A., \& Haston, M. (2010). The personal is political: School counselors' use of self in social justice advocacy work. Journal of School Counseling, 8(18). Retrieved from http://www.jsc.montana.edu/articles/v8n18.pdf.

National Center for Transgender Equality. (2010). Take action for transgender equality. Retrieved from http://www.transequality.org/take_action/takeaction.html. 
National Gay and Lesbian Task Force. (2010). Activist resource center and tools. Retrieved from http://www.thetaskforce.org/activist_center/resources_and_tools

Owens, A., Doolin, E., Downes, J., Graham, S., Harper, A., \& Hatchman, B. (2006, February). Reexamining the straight agenda: Creating a supportive campus environment. Presented at the $2^{\text {nd }}$ Annual Day of Learning: GLBTQI Issues in Counseling \& Education, Georgia State University, Atlanta, GA.

Rostosky, S. C., Riggle, E. B., Brodnicki, C., \& Olson, A. (2008). An exploration of lived religion in same-sex couples from Judeo-Christian Traditions. Family Process, 47, 389-403.

Singh, A. A. (2010). It takes more than a rainbow sticker! Using the ACA Advocacy Competencies with queer clients. In M. Ratts, J. Lewis, \& R. Toporek (Eds.), Using the ACA Advocacy Competencies in counseling (pp. 29-41). Alexandria, VA: American Counseling Association.

Singh, A. A., Boyd, C. J., \& Whitman, J. S. (2010). Counseling competency with transgender and intersex individuals. In J. Cornish, L. Nadkarni, B. Schreier, \& E. Rodolfa (Eds.), Handbook of multicultural competencies (pp. 415-442). New York, NY: Wiley \& Sons.

Singh, A. A., \& Johnson, C.W. (Producers). Kaneria, R., \& Kaneria, J. (Filmmakers). (2009). Be there for me": Collective memories of LGBTQ youth in high school [Documentary]. United States.

Singh, A. A., \& Johnson, C.W. (Producers). Roberts, J., \& Sykes, A. (Filmmakers). (in production). We exist: Collective memories of transgender youth in Georgia high schools [Documentary]. United States.

Singh, A. A., Urbano, A., Haston, M., \& McMahon, E. (2010). School counselors' strategies for social justice change: A grounded theory of what works in the real world. Professional School Counseling, 13, 135-145.

Smith, R. (Ed.) (2001). The Encyclopedia of AIDS: A social, political, cultural, and scientific record of the HIV epidemic, New York, NY: Penguin Reference. (Original work published 1998).

Sue, D., Bucceri, J., Lin, A. I., Nadal, K. L., \& Torino, G. C. (2007). Racial microaggressions and the Asian American experience. Cultural Diversity and Ethnic Minority Psychology, 13(1), 72-81. doi:10.1037/1099-9809.13.1.72

Theoharis, G. (2007). Social justice educational leaders and resistance: Toward a theory of social justice leadership. Educational Administration Quarterly, 43(2), 221-258. doi:10.1177/0013161X06293717

West-Olatunji, C. A., \& Watson, Z. E. P. (1999). Community-as-client mental health needs assessment: Use of culture-centered theory and research. The Community Psychologist, 32, 36-38. 
Whitman, J. S., Glosoff, H. L., Kocet, M. M., \& Tarvydas, V. (2006, May 22). Ethical issues related to conversion or reparative therapy. ACA in the News. Retrieved from http://www.counseling.org

Wynn, R., \& West-Olatunji, C. (2008). Use of culture-centered theory with ethnically diverse LGBT clients. Journal of LGBT Issues in Counseling, 3, 198-214. 